\title{
Patent Examination and Examiner Interviews
}

S. Sean Tu

Follow this and additional works at: https://researchrepository.wvu.edu/law_faculty

Part of the Intellectual Property Law Commons 


\title{
PATENT EXAMINATION AND EXAMINER INTERVIEWS
}

\author{
S. SEAN TU1
}

\begin{abstract}
Examiner interviews are one of the most powerful tools to help both inventors and examiners understand and overcome specific issues during prosecution. Direct discussions between an applicant and an examiner can help bridge the gap between misunderstandings of prior art, the invention, or statements in the specification. When used correctly, examiner interviews can dramatically decrease the time in prosecution and help applicants quickly reach a final disposition. This paper reviews approximately 1.1 million patent applications corresponding to every patent application with an examiner interview between 2007 and June 2020 to determine the effectiveness of examiner interviews. This study establishes that examiner interviews dramatically decrease the number of Office Actions needed to reach a final disposition (allowance or abandonment).
\end{abstract}

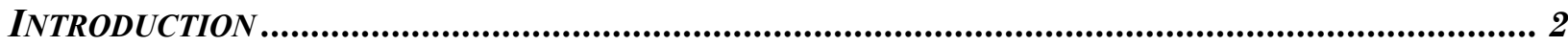

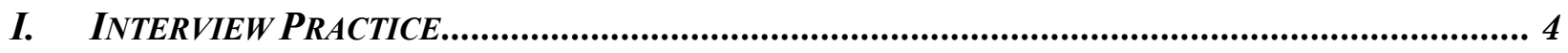

A. General Information About Interview Practice ................................................................... 5

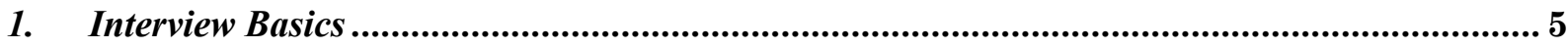

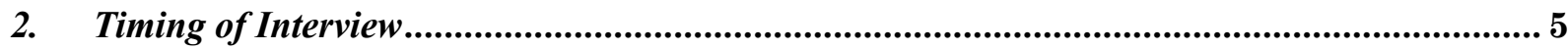

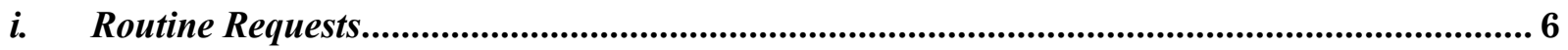

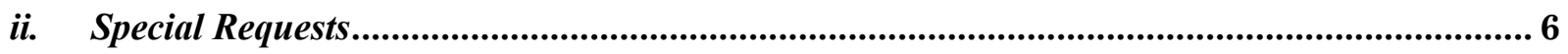

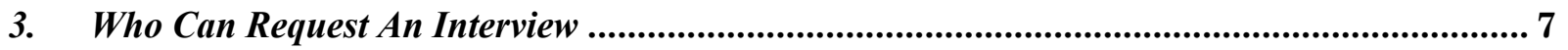

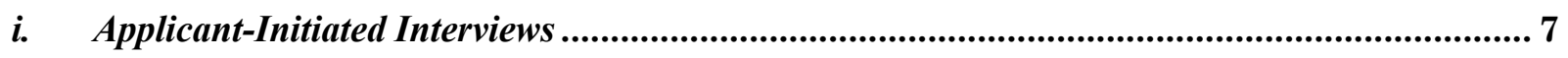

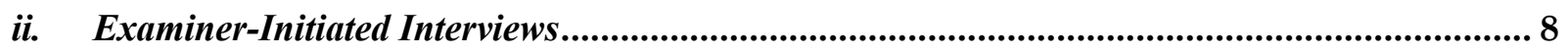

4. Who Can Participate in An Interview ........................................................................................ 8

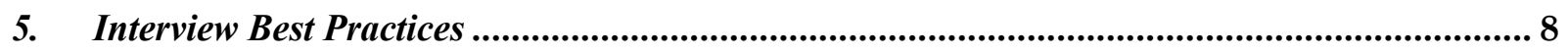

B. Streamlining Access to Interview Practice .................................................................................. 9

1. Automated Interview Request (AIR) Tool ................................................................................ 10

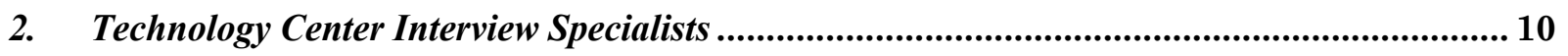

C. USPTO Incentives for Interview Practice .............................................................................. 10

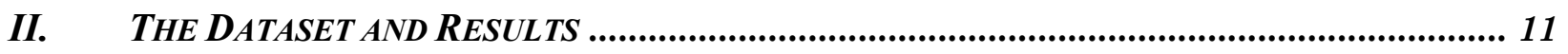

\footnotetext{
${ }^{1}$ Professor, West Virginia University College of Law. The data for this work was provided by PatentAdvisor.com. This work was funded in part by the generous support of the West Virginia University College of Law Hodges Research Fund. Sincere thanks to the many readers who offered comments on earlier drafts, including Mark Lemley, Jake Lindford, Anne Lofaso and workshops at the Campbell Law School and the $18^{\text {th }}$ Annual Works-in-Progress Intellectual Property Colloquium.
} 
A. Office Action to Grant Ratio (OGR) / Office Action to Abandonment Ratio (OAR)

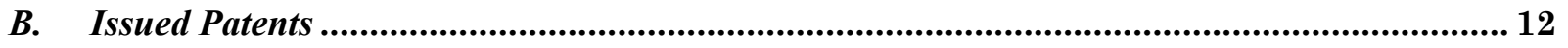

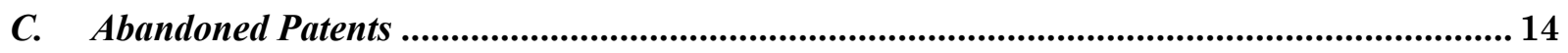

III. IMPROVING INTERVIEW PRACTICE ...................................................................... 17

A. Rationales for How Interviews Compact Prosecution ......................................................... 17

1. Interviews Used to Bridge the Gap ............................................................................................ 17

2. Interviews as a Signal ............................................................................................................ 17

B. Possible Improvements to Interview Practice ............................................................................ 18

1. Require Proposed Claim Language from Both Applicants and Examiners............................. 18

2. Create a More Detailed Interview Summary ............................................................................ 19

3. Tie Interview Practice to Examiner Promotion ....................................................................... 20

4. Increase the Examiner Time Allotted for Interview Practice ................................................ 20

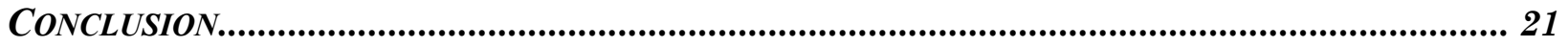

\section{INTRODUCTION}

Examiner interviews are one of the most powerful tools to help both inventors and examiners understand specific issues during prosecution. Direct discussions between an applicant and an examiner can help bridge the gap between misunderstandings of prior art, details regarding the invention, or statements in the specification. Additionally, once these misunderstandings are cleared up, interviews can be a chance for examiners to suggest claim amendments to traverse those rejections. When used correctly, examiner interviews can dramatically decrease the time in prosecution and help applicants quickly reach a final disposition.

Patent examination, at its heart, is a negotiation between the patent examiner and the applicant. ${ }^{2}$ One of the most powerful tools to help facilitate this negotiation is interview practice, which allows both parties to sit down face-to-face and talk through specific issues that may be hindering progress towards a final disposition. This "face-to-face" conversation with the examiner is called an "Examiner Interview" (hereinafter "Interview"). Interviews can be completed in a number of ways, such as in person, telephonically, or via online visual conversations. ${ }^{3}$ No matter which venue is chosen, examiner interviews can compact prosecution by helping both parties understand where they are coming from. Below is a real example of how interview practice can shorten prosecution times.

Dr. Anthony Letai is a physician and professor at the Harvard Medical School and DanaFarber Cancer Institute who filed a patent application (U.S. 13/478,831) for a new method of identifying how sensitive a cancer cell is to a therapeutic agent by treating it with a host of chemicals before testing to see how the cell reacts. ${ }^{4}$ This application was assigned to Patent

\footnotetext{
2 Kevin Johnston, Reasons to Avoid the Anchor: Negotiation in Patent Prosecution, 2020 J. DisP. RESOL. 467 (2020).

3 The vast majority of interviews are conducted telephonically. Personal communication Michael Their (Supervisory Patent Examiner Art Unit 2474 - Multiplex Communications), September 22, 2020.

${ }^{4}$ See Anthony Letai, M.D., P.h.D, DANA-FARBER CANCER InSTITUTE, https:/letailab.dana-farber.org/anthony-letai.html (last visited July 26, 2020).
} 
Examiner Aeder, who rejected the application based on prior art as well as based on nonstatutory double patenting (NSDP) grounds. ${ }^{5}$ Dr. Letai addressed the prior art issues by amending the claims, arguing that the prior art does not teach or suggest each and every element of the claims, and stating that the examiner "misread" and "mischaracterized" the claimed invention. ${ }^{6}$ The examiner was not persuaded by Dr. Letai's arguments and retained the prior rejection and the NSDP rejection. The application then went back and forth three additional cycles, with the applicant amending claims and the examiner sustaining his rejection(s). All told, after four office actions and 757 days $^{7}$ (2.10 years), Dr. Letai obtained a patent.

Robert Carraway is a physician at the University of Massachusetts Medical School who filed a patent application (U.S. 12/330,035) for a new method of identifying antioxidants by contacting a test compound to a cell before monitoring the level of a chemical within the cell. 8 This application was also assigned to Patent Examiner Aeder, who rejected the application based on failure to comply with the written description requirement as well as an anticipatory prior art rejection and a NSDP rejection. ${ }^{9}$ Before responding to the examiner, the applicant conducted an examiner interview where the applicant and examiner discussed the prior art rejections as well as the written description rejection. Furthermore, during this interview, the examiner suggested language and amendments that would help improve the claims. ${ }^{10} \mathrm{Dr}$. Carraway incorporated the suggestions made by the examiner, and, in the next action, the examiner allowed the case. After only one office action and 269 days ${ }^{11}$ (0.73 years), Dr. Carraway obtained a patent.

Despite the speedier resolution of Dr. Carraway's patent, both applications were remarkably similar. Both claimed priority to a parent application, dealt with loosely similar technology, ${ }^{12}$ had similarly experienced attorneys, and were assigned to the same examiner. ${ }^{13}$ Furthermore, the type of rejections faced in both cases were also similar. Both applications faced several prior art rejections as well as an NSDP rejection. ${ }^{14}$ One big difference during prosecution, however, was Dr. Carraway's use of interview practice. The interview seemed to allow both parties to get on the same page when it came to the substance of the rejections as well as allowed the examiner to suggest possible amendments to overcome those rejections. Once the proffered amendments were made, Dr. Carraway's application was allowed. In the absence of the examiner interview, it took three additional actions and over an additional year before Dr. Letai was able to receive his patent. Foregoing the use of an examiner interview could be one significant reason why it took longer for Dr. Letai to obtain a patent.

\footnotetext{
${ }^{5}$ See U.S. Patent application 13/478,831 (filed May 23, 2012), where the application was first rejected on 35 U.S.C. §102(b), 103, and a non-statutory double patenting rejection.

${ }_{6}^{6}$ See U.S. Patent prosecution history 13/478,831, Applicant Arguments/Remarks Made on April 15, 2015, page 8.

${ }^{7}$ Measured from the restriction requirement to the notice of allowance.

8 See ROBERT CARROWAY, https://www.linkedin.com/in/carraway-robert-573ab84b/ (last visited July 26, 2020).

9 See U.S. Patent application 12/330,035 (filed December 8, 2008), Non-Final Rejection dated June 4, 2010.

${ }_{10}$ See U.S. Patent application 12/330,035, Applicant Arguments/Remarks Made in an Amendment dated September 30, 2010 and Examiner Interview Summary Record dated October 4, 2010.

11 Measured from the restriction requirement to the notice of allowance.

${ }_{12}$ Both claims deal with a new identification method by adding a foreign substance to a cell before measuring the outcome of that interaction.

${ }^{13}$ Patent Examiner Aeder only had approximately four years of experience as an examiner in 2008 and eight years of experience in 2012. Previous studies have shown that more experienced examiners have a higher allowance rate. See Shine Tu, Luck/Unluck of the Draw: An Empirical Study of Examiner Allowance Rates, 2012 STAN. L. Rev. 10 (2012). Accordingly, this example shows that interviews may play an even more important role in reducing examination times.

14 U.S. Patent application 13/478,831 did, however, receive an additional patentable subject matter rejection based on 35 U.S.C. $§ 101$.
} 
Speedy disposition of a patent application should be the goal both applicants and the Patent and Trademark Office. Previous studies have shown that patent pendency is a crucial aspect of intellectual property rights and affects a company's ability to obtain start-up financing as well as increased sales and employment growth. ${ }^{15}$ Unfortunately, many applications languish in prosecution simply because the applicant does not correctly understand the issues and rejections raised by the examiner and/or the examiner does not understand the arguments/amendments made by the applicant to traverse the rejections. Because of these misunderstandings, patent prosecution can be prolonged for months and, in many cases, years before reaching a final disposition (e.g., allowance or abandonment). This can become increasingly important for large patent filers since each response, on average, costs approximately $\$ 3,000 .{ }^{16}$ Examiner interviews bridge the gap between the applicant and examiner; they allow the applicant to better understand the examiner's rejection while also allowing the examiner to better understand the applicant's arguments.

This study empirically assesses the benefits and costs of using an examiner interview during prosecution. This study reviews every patent application filed with an interview between 2014-2019 (over one million applications) and determines the average number of office actions required to obtain a final disposition. These data are then compared with the examiner's average disposition rate. When compared to the examiner's average disposition rate, this study finds examiner interviews dramatically decrease the number of Office Actions necessary to get to a final disposition.

Part I of this article describes examiner interview practice, focusing on the different types of interviews as well as how applicants go about requesting interviews. Part II explains the dataset created to investigate examiner interviews and describes the results from this study. Part III gives suggestions on how to optimize and incentivize these interviews.

\section{INTERVIEW PRACTICE}

Examiner interviews allow the applicant and examiner to clarify positions, resolve issues, and provide a better understanding of the application as well as prior art. Interviews are conducted to help advance prosecution and identify patentable subject matter as well as help the applicant and examiner understand their corresponding rejections and traversal arguments. ${ }^{17}$ Additionally, the interviews are meant to be a collaborative effort between the applicant and examiners to help compact advance prosecution. ${ }^{18}$

There are two major benefits for the applicant when using interviews. First, it allows for real-time discussion with the examiner, and possibly their supervisor, to hash out substantive matters at issue in an application. Second, interviews typically do not create a detailed prosecution history. Although interviews are technically on record, the record usually does not contain too much detail about what was discussed. Individual claims and arguments, which are much more likely to be heavily scrutinized and create issues, are seldom recorded in great detail in the "Interview Summary" document. Accordingly, applicants typically do not have issues with

\footnotetext{
15 Dietmar Harhoff \& Stefan Wagner, The Duration of Patent Examination at the European Patent Office, 55 MANAGEMENT SCIENCE 1969 (2009). Joan Farre-Mensa, Deepak Hegde, \& Alexander Ljungqvist, What is a Patent Worth? Evidence from the U.S. Patent "Lottery", 75 J. of FinAnCe 639 (2020). Deepak Hegde, Manav Raj, \& Alexander Ljungqvist, Quick or Broad Patents? Evidence from U.S. Startups, available at SSRN 3511268.

162019 American Intellectual Property Law Association Economic Survey Benchmark Tool.

17 See Interview Best Practices, USPTO,

https://www.uspto.gov/sites/default/files/patents/law/exam/interview_best_practices.pdf.

${ }_{18}$ Id. ("Examiners and applicants should not conduct interviews as adversaries, but rather, should conduct interviews with the objective of meeting the common goals of advancing prosecution and resolving issues.”).
} 
prosecution history estoppel when discussing prior art or the claimed inventions in an interview.

\section{A. General Information About Interview Practice}

Since 2008, the absolute number of interviews has dramatically increased. Specifically, in 2008 there were less than 80,000 hours spent on interviews. However, in 2019, there were more than 260,000 hours recorded for interviews. ${ }^{19}$ Additionally, the number of hours spent per examiner on interviews has increased commensurately from less than sixteen hours per examiner in 2008 to approximately thirty-two hours per examiner in $2019 .{ }^{20}$ Finally, in 2008 less than $20 \%$ of disposed cases had at least one interview, whereas in 2019 this number increased to more than 35\%. ${ }^{21}$ Accordingly, an increasing number of examiners are spending time conducting interviews, and more applications that have at least one interview are disposed (allowed, abandoned, or appealed).

\section{Interview Basics}

The rules for examiner interviews are governed by the PTO's Manual of Patent Examining Procedure (MPEP) 713. Interviews can occur in several different ways: in person, via telephone, video conference, electronic mail, or electronic instant message system using USPTObased collaboration tools. The USPTO notes that internet email, instant messages, or video conferences are not secure. Accordingly, the examiner is required to obtain either written or oral authorization from the applicant acknowledging that these communications are not secure. ${ }^{22}$

Interviews are usually scheduled one to four weeks in advance and are held during business hours (Monday through Friday 8:30 a.m. - 5:00 p.m.) unless otherwise agreed upon by all participants. Typically, examiner interviews last only about thirty minutes. ${ }^{23}$ Examiners receive sixty minutes of non-production time credit for interviews and typically spend thirty minutes preparing for the interview and thirty minutes conducting the interview.

Applicants may bring demonstrations, exhibits, and models; however, these items will not be generally admitted as part of the record unless it complies with 37 CFR 1.91.24 Although an agenda is not required, the examiner will typically request that the applicant provide an agenda for the interview to facilitate a focused discussion on the issues. The agenda typically includes information about the references, claims, or specific rejections the applicant wishes to discuss, as well as any proposed amendments or evidence that the applicant will be providing.

\section{Timing of Interview}

\footnotetext{
${ }^{19}$ See PTO Interview Policy Presentation "Partnering in Patents: Interview Practice," Tariq Hafiz, Director Technology Center 3600 (Slide 6).

${ }^{20}$ See PTO Interview Policy Presentation "Partnering in Patents: Interview Practice," Tariq Hafiz, Director Technology Center 3600 (Slide 7).

${ }^{21}$ See PTO Interview Policy Presentation "Partnering in Patents: Interview Practice," Tariq Hafiz, Director Technology Center 3600 (Slide 8).

22 See U.S. Dep’t of Commerce, Patent \& Trademark Office, Manual of Patent Examining Procedure $§ 713.01$ (9th ed., Rev. 10, June 2020) [hereinafter MPEP]; Authorization can be given by EFS WEB (SB/0439), central fax, U.S. Postal Service, or a USPTO customer service window (email does not constitute authorization under current USPTO policy). MPEP 713.01(II).

${ }^{23}$ See MPEP $\S 713.01$ (It is the "responsibility of all participants to see that the interview is not extended beyond a reasonable period, usually 30 minutes.”).

${ }^{24}$ See MPEP $\S$ 608.03-608.03(a).
} 
After the issuance of a first Office Action, the patent examiner must grant an interview as a matter of right if an interview is requested by the applicant. An applicant can only request an interview prior to the first Office Action in continuing or substitute applications. ${ }^{25}$ Accordingly, most interviews occur after the first Office Action. This allows both parties to consider the current rejections as well as any prior art if there were anticipation and/or obviousness rejections. Examiners are "encouraged to have an interview whenever the interview can resolve issues and help further prosecution." 26 However, examiners usually only initiate interviews to suggest claim amendments, thereby concluding prosecution.

Generally, interviews are not permitted before the first office ${ }^{27}$ action or after submission of an appeal brief or after a notice of allowance. ${ }^{28}$ Interviews, however, may be permitted after the final rejection but before the notice of appeal. ${ }^{29}$ These interviews should help place the application for allowance or to resolve issues prior to appeal. Interviews during this period will not be granted if the applicant simply wants to restate the arguments of record or to discuss new limitations that would require "more than nominal reconsideration or [a] new search." 30

\section{i. $\quad$ Routine Requests}

Although applicants do not have a right to an interview after a final rejection, the examiner can choose whether to allow one. ${ }^{31}$ The examiner has the discretion to grant the interview if she believes it will move prosecution forward and if the interview serves to develop or clarify outstanding issues in an application. Accordingly, an examiner may not grant an interview if the applicant simply wants to make arguments found in a previous response. An examiner may be more predisposed to granting an interview that proposes new claim amendments along with new arguments.

Interviews are generally not permitted after an application is sent to issue because it is no longer under the jurisdiction of the primary examiner. ${ }^{32}$ In rare instances, however, an interview may be granted with specific approval of the Technology Center Director upon a showing of extraordinary circumstances. ${ }^{33}$

\section{ii. $\quad$ Special Requests}

Although most interviews occur between a non-final and final rejection, there are a few programs that allow for interviews outside the norm. There are two programs where the applicant can request an interview before the first Office Action. Applicants who seek prioritized examination can request an interview with the examiner prior to the first Office

\footnotetext{
${ }^{25} I d$. at MPEP $\S 713.02$.

${ }^{26}$ Id. at MPEP $\S \S 713.05$ and MPEP 713.10. See also Interview Practice FAQs, InTERVIEW PRACTICE FAQs, https://www.uspto.gov/patents/laws/interview-practice/interview-practice-faqs (last visited April 11, 2021).

${ }_{27}$ See infra Appendix 4 below (First Action Interview Pilot Program) for an exception to this general rule.

${ }^{28}$ See MPEP $\S 713.10$. However, interviews are allowed in these situations under "extraordinary circumstances" and should

be granted only with specific approval of the Technology Center Director. Id.

${ }^{29}$ Id. at MPEP § 713.09.

${ }^{30} I d$. at MPEP $\S 713.09$.

${ }^{31} I d$.

32 Id. at $\S 713.10 ; 37$ CFR 1.132 .

${ }^{33}$ MPEP $§ 713.10$.
} 
Action. ${ }^{34}$ Additionally, those who are participating in the "Full First Action Interview Pilot Program" are entitled to a first action interview prior to the first Office Action. ${ }^{35}$

If the applicant wishes to conduct an interview after a final rejection, they can request to participate in the After Final Consideration Pilot 2.0 (AFCP 2.0). 36 Under the AFCP 2.0 program, the examiner will receive extra time to search and/or consider responses after a final rejection. ${ }^{37}$ Additionally, the examiner may conduct an interview to discuss the results of their search and any remaining issues the examiner may have with the claims.

\section{Who Can Request An Interview}

The PTO normally will not grant the interview unless the requesting party has the ability to bind the principal concerned. ${ }^{38}$ Similarly, if the application is being examined by a junior examiner without primary signatory authority, then the requesting party should always include an examiner who is familiar with the application and has signatory authority so that an authoritative agreement may be reached at the end of the interview. ${ }^{39}$

There are two main types of interviews: applicant-initiated interviews and examinerinitiated interviews.

\section{i. $\quad$ Applicant-Initiated Interviews}

Generally, only the applicant or the attorney or agent of record can request an interview (applicant-initiated interview). ${ }^{40} \mathrm{~A}$ party with the mere power to inspect an application is not sufficient to grant an interview. Interviews may, however, be granted to registered attorneys or agents who are not of record if they are acting in a representative capacity for the applicant under 37 CFR 1.34. ${ }^{41}$

After the first Office Action, the applicant can request an interview as a matter of right. 42 There are three methods to submit requests: (1) simply filling out a PTOL-413A form, which is the USPTO's preferred method; (2) using the USPTO's online Automated Interview Request (AIR) system; or (3) directly calling the examiner to request an interview. ${ }^{43}$ Although the USPTO prefers applicants request interviews through the PTOL-413A form, applicants can

\footnotetext{
${ }^{34} I d$. at $\S 708.02(\mathrm{~b})$.

${ }^{35}$ First Full Action Interview Pilot Program, USPTO, https://www.uspto.gov/patent/initiatives/first-action-interview/full-firstaction-interview-pilot-program (last visited August 4, 2020). See also infra Appendix 4.

36 The AFCP 2.0 program is a pilot program that has been extended through September 30, 2021. The program aspires to compact prosecution and increase collaboration between examiners and stakeholders. To participate in the AFCP 2.0 program the applicant need only do the following: (1) fill out Form PTO/SB/434 and an amendment to at least one independent claim that does not broaden the scope of the independent claim in any aspect; (2) make a statement showing a willingness to participate in an interview; and (3) pay any necessary fees. See 78 Fed. Reg. 29117-02.

${ }_{37}$ After Final Consideration Pilot 2.0, USPTO, https://www.uspto.gov/patents/initiatives/after-final-consideration-pilot-20 (visited July 15, 2021).

38 MPEP $§ 713.05$.

${ }^{39} I d$.

${ }^{40}$ See id.

${ }^{41}$ See $i d$. at $\S 402.04$.

${ }^{42}$ Additionally, if the applicant files an RCE, after the first non-final office action, the applicant has the right to request another interview. See MPEP § 713.05.

${ }^{43}$ See Interview Practice, United States Patent and Trademark Practice (Nov. 8, 2017), www.uspto.gov/interviewpractice. USPTO, www.uspto.gov/interviewpractice.
} 
request an interview through informal means such as simply calling the examiner to request an interview. ${ }^{44}$

\section{ii. Examiner-Initiated Interviews}

Conversely, examiners can also request interviews from applicants (examiner-initiated interviews). Only an examiner with a GS-12 or higher with negotiation authority has the ability to conduct an interview. Interestingly, an examiner usually only contacts the applicant for an interview when the application is close to allowance. ${ }^{45}$ Examiner-initiated interviews are usually requested to discuss proposed amendments that would lead to allowance. Accordingly, for most applications, this study finds no more than one examiner-initiated interview per application, unlike applicant-initiated interviews which contain nearly twice as many interviews.

\section{Who Can Participate in An Interview}

Interviews are mainly conducted by patent agents or patent attorneys who are registered to practice in front of the USPTO and represent the applicant. Interviews are typically not granted to a registered practitioner unless the applicant has granted the practitioner a power of attorney. ${ }^{46}$ If the interview is conducted to discuss procedural or legal issues, then it may be appropriate for only the prosecuting attorney or agent to attend.

Inventors/applicants can also participate in interviews with an examiner. Inventors/company representatives may be helpful if the interview is conducted to discuss complex technical issues and/or provide the examiner with a better understanding of the claimed invention or general technology. Similar to inventors/applicants, a pro-se applicant may conduct an interview even in the absence of a registered practitioner. Sometimes it is helpful for the inventor/applicant to attend the interview because they are experts in the field and can help distinguish the invention over the prior art. However, many inventors/applicants are not familiar with patent law and should be cautioned against making unnecessary statements that could create estoppel issues.

Examiners and their supervisors are, obviously, a critical component of the interview. The direct "working" examiner who is responsible for application will participate in the interview. If the examiner is a junior examiner (usually defined as being below a GS-12 and without negotiation authority), the applicant should request that the examiner's supervisor who is familiar with the application to participate in the interview. This is important because a junior examiner who does not have negotiation authority cannot reach an authoritative agreement at the time of the interview, which is the impetus behind having the interview in the first place.

\section{Interview Best Practices}

\footnotetext{
${ }^{44}$ Registered practitioners who are acting in a representative capacity can show authorization to conduct an interview by completing, signing and filing an Applicant Initiated Interview Request Form (PTOL-413A). Alternatively, Form PTO/SB/84, "Authorization to Act in a Representative Capacity" may also be used to establish the authority to conduct an interview. ${ }^{45}$ Personal communication with Technology Center Interview Specialist.

${ }^{46}$ Unregistered or suspended practitioners are barred from conducting interviews because examiners are forbidden to have either oral or written communications with an unregistered or suspended attorney or agent regarding an application (unless the application is one in which the attorney or agent is an inventor or the applicant). See MPEP $§ 105$ and $§ 407$.
} 
Once an interview is granted, the examiner typically requests the applicant provide a detailed agenda along with any proposed amendments, arguments, or evidence that the applicant wishes to discuss at the interview. This written agenda becomes part of the file history. The examiner then prepares for the interview by evaluating the claims and prior art to assist the applicant in identifying allowable subject matter. Additionally, both the examiner and applicant can propose claim amendments and fallback positions that could result in allowance. Finally, both the examiner and applicant should be prepared to explain the rationale for any positions taken in the interview.

During the interview, both the examiner and applicant should look for opportunities to resolve as many outstanding issues as possible. Examiners should articulate why proposed amendments do not overcome a rejection of record. Similarly, applicants should explain why any examiner-suggested claim amendments are objectionable. Finally, if an agreement can be reached, both the examiner and applicant should be able to bind their respective parties at the end of the interview.

To conform with 37 C.F.F 1.2, the oral discussions between applicant and examiners during the interview are summarized in writing. A complete recordation of the substance of an interview should include: identification of the claims discussed; identification of the specific prior art discussed; and an indication of whether an agreement was reached and, if so, a description of the general nature of the agreement. 47 No agreements, promises, stipulations, or understandings will be recognized that are not on the written record at the USPTO. After the interview, the examiner and applicant must each draft an interview summary. ${ }^{48}$ However, this summary is typically short and seldom describes the specific issues discussed during the interview.

Many times, the examiner's interview summary is completed at the end of the interview with input from the applicant. Accordingly, the applicant usually requests the most general description of the interview, such as "prior art was discussed" or "anticipation and obviousness rejections and arguments were discussed." If an agreement was reached, many descriptions can be as simple as "amended claims overcome prior art issues." Applicants, of course, would prefer a brief summary, especially if an agreement was not reached, due to the specter of prosecution history estoppel. Similarly, if the proposed amendments lead to an allowance, applicants will want to frame the interview in the most favorable light by minimizing the breadth of any estoppel issues.

Finally, even if an agreement is reached during the interview, the examiner will conduct a final update and interference search. This search could produce prior art that would negate the patentability agreement reached in the interview. 49

\section{B. Streamlining Access to Interview Practice}

The PTO has created programs to help streamline access to interview practice. Two prominent programs are: (1) the Automated Interview Request tool and (2) the technology center interview specialists.

\footnotetext{
${ }^{47}$ See MPEP $\S 713.04$.

48 The applicant is not, however, expected to write a separate summary of the interview if the examiner indicates in writing on the PTOL-413 form that a written summary of the interview by the applicant is not necessary. See Interview Best Practice, UNITED STATES PATENT AND TRADEMARKS OFFICE, 8 (2020),

https://www.uspto.gov/sites/default/files/patents/law/exam/interview_best_practices.pdf.

${ }^{49}$ MPEP § 719.05; MPEP § 904; MPEP § 1302.08.
} 


\section{Automated Interview Request (AIR) Tool}

The USPTO has created the Automated Interview Request (AIR) tool which allows applicants to request an interview with the examiner and propose a date that is between five and thirty-five days after submission date. The applicant provides basic information, including the application number, type of interview (in-person, telephonic, or video conference), and the registration number of the applicant's representative. Additionally, the applicant will submit a proposed interview time and date along with two alternative dates. Finally, the applicant can optionally include an agenda or list topics for discussion. The AIR tool is especially useful when applicants are not able to get in touch with the examiner by phone.

\section{Technology Center Interview Specialists}

Each technology center has at least one interview specialist. 50 These specialists are subject matter experts on interview practice and policy. They assist in interviews and can facilitate or assist with technical issues that may arise. For example, interview specialists can help applicants with the WebEx application and other technical challenges. ${ }^{51}$ The specialists can also train examiners in how to conduct an interview and how to use the necessary technology.

\section{USPTO Incentives for Interview Practice}

USPTO recognizes that these interviews can help compact prosecution and identify allowable subject matter earlier in the examination process. Accordingly, the USPTO incentivizes examiners to give interviews. The "count" system ${ }^{52}$ gives "non-production time" credit for substantive examiner-initiated interviews as well as applicant-initiated interviews. This includes time for preparing for the interview, conducting the interview, and completing the post-interview documentation.

Currently, the USPTO does not give additional counts for interview practice. However, the examiner is given one hour of non-production credit towards interview practice. Typically, the examiner will spend 30 minutes of time on the actual interview and 30 minutes or more preparing for the interview as well as documenting what occurred during the interview. As previously mentioned in Section I(A), the number of hours spent on interviews by examiners increased from 80,000 hours in 2008 to over 260,000 hours in 2019. 53 Accordingly, the USPTO has invested tens of millions of dollars into giving examiners time for interviews during examination.

\footnotetext{
${ }^{50}$ Interview Specialist, United States PATENT AND Trademarks OfFice, (Nov. 8, 2018), https://www.uspto.gov/patent/lawsand-regulations/interview-practice/interview-specialist. [TC1600, TC1700, TC2100, TC2900, and TC3600 each have three specialists; TC2400 has five specialists; TC2600 and TC3700 have four specialists; TC 2800 has six specialists; and TC 3900 has two specialists. Additionally, each of the USPTO satellite offices have at least one specialist.]

51 For example, the video for WebEx is achieved through the user's computer, however the audio is accomplished through the applicant's phone.

${ }^{52}$ For a complete discussion of the count system, see also Simmons, N.R., Putting yourself in the Shoes of a Patent Examiner: Overview of the United States Patent and Trademark Office (USPTO) patent Examiner Production (Count) System, 17 J. Marshall Rev. Intell. Proper. L. 32 (2017). Examiners were given credit for examiner-initiated interviews as part of the count reform package implemented on November 9, 2009. See also Blatt, E.D. and Huang, L., Do Heightened Quality

Incentives Improve the Quality of Patentability Decisions? An Analysis of Trend Divergences During the Signatory Authority Program, 46 AIPLA QUARTERLY J. 161 (2018).

${ }^{53}$ See Tariq Hafiz, PTO Interview Policy Presentation: "Partnering in Patents: Interview Practice," Slide 6.
} 


\section{The DATASET AND RESUlts}

This dataset focuses on all applications that contained an examiner interview during a thirteen-year period from January 2007 to June 2020. This study hypothesized that examiner interviews would help the application get to a final disposition in fewer office actions than those applications without an examiner interview. Accordingly, this dataset contains: (1) 1,008,989 applications that had at least one interview and were subsequently issued a patent and (2) 146,851 applications that had at least one interview and were subsequently abandoned by the applicant. We compare these data with the allowance rate and abandonment rates associated with the paired examiners. These data were then segmented by technology center to determine if there were technology effects associated with interview practice.

The data was segmented by Technology Center. The dataset includes examiners from the following Technology Centers associated with the corresponding technology types:

\begin{tabular}{|l|l|}
\hline Technology Center & Technology Type \\
\hline Technology Center 1600 & Biotechnology and Organic Chemistry \\
\hline Technology Center 1700 & Chemical and Materials Engineering \\
\hline Technology Center 2100 & Computer Architecture, Software, and Information Security \\
\hline Technology Center 2400 & $\begin{array}{l}\text { Computer Networks, Multiplex Cable and Cryptography / } \\
\text { Security }\end{array}$ \\
\hline Technology Center 2600 & Communications \\
\hline Technology Center 2800 & $\begin{array}{l}\text { Semiconductors, Electrical and Optical Systems and } \\
\text { Components }\end{array}$ \\
\hline Technology Center 3600 & $\begin{array}{l}\text { Transportation, Construction, Electronic Commerce, } \\
\text { Construction, Agriculture, Licensing and Review }\end{array}$ \\
\hline Technology Center 3700 & Mechanical Engineering, Manufacturing and Products \\
\hline
\end{tabular}

The dataset excluded design patents (Technology Center 2900).) to focus on only utility patents.

Additionally, this study collected information about the party who initiated the interview. Specifically, information was gathered about interviews initiated by the applicant (by coding for those applicants who used a PTOL-413A form) and interviews initiated by the examiner (by coding for those examiners who used a PTOL-413B form). Those applicants who scheduled an interview but did not use a PTOL-413A form are captured in the "total interviews" number. ${ }^{54}$

The data from applicant and examiner-initiated interviews also contains the specific number of applicant- or examiner-initiated interviews. Accordingly, for each application, we know if there were one, two, three, or more applicant-initiated interviews, and likewise for the examiner-initiated interviews. Thus, unlike the total allowance data, the data pulled for applicant and examiner interviews (cases containing PTOL-413A and 413B forms respectively) track the exact number of interviews conducted before allowance or abandonment. Accordingly, this study determines, on average, how many applicant or examiner-initiated interviews are necessary before a final disposal (allowance or abandonment).

\footnotetext{
54 The "total interviews" number is the sum of (1) applicant initiated interviews (interviews with a PTOL-413A form), (2) examiner initiated interviews (interviews with a PTOL-413B form) and (3) those interviews that did not have either a PTOL413A or PTOL-413B form.
} 
For each application with an interview that led to an allowance, this study recorded: (1) the number of office actions it took before a notice of allowance for the instant case, (2) the number of non-final office actions for the instant case, and (3) the number of final office actions for the instant case. Additionally, this study coded the overall statistics for those same examiners. Specifically, this study recorded: (1) the total averaged Office Action to Grant Ratio (OGR) for the specific examiner, (2) the total averaged Office to Abandonment Ratio (OAR), (3) the allowance rate for the specific examiner, and (4) the abandonment rate for the specific examiner.

\section{A. Office Action to Grant Ratio (OGR) / Office Action to Abandonment Ratio (OAR)}

The Office Action to Grant Ratio (OGR) and Office Action to Abandonment Ratio (OAR) allows the reader to quickly understand how many Office Actions it takes to reach a final disposition. ${ }^{55}$ Specifically, the average OGR score determines how many Office Actions it takes before an examiner grants a patent. Similarly, the average OAR score determines how many Office Actions it takes before an applicant abandons an application.

OGRs and OARs are better metrics for patent prosecution duration than just looking at overall time. This is because applicants typically have between three to six months to reply to an Office Action. ${ }^{56}$ Similarly, examiners have a variable time period in which they can respond to the applicant's response. Simply measuring the duration between the filing date and issue date can be misleading because there can be significant variation in prosecution times created by delays on both the applicant and examiner sides. OGR and OAR measures the number of actions taken by the examiner, which is independent of the delays that might be created by either the applicant or examiner. This is especially important when it comes to cases with interviews because there may be selection bias created by cases that are interviewed. Specifically, those applications with interviews may contain complex technologies, problematic prior art, or have already gone through several rounds of RCEs.

\section{B. Issued Patents}

To determine the effect of interviews on prosecution times, this study compares the OGR rates for those cases with interviews versus the corresponding total OGR rates for those same examiners. Accordingly, the OGR value for each interviewed application is compared against the overall OGR rate for that same examiner. This pair-wise analysis prevents bias from incorporating data from those examiners who do not interview any applications.

Figure 1 shows that cases with interviews have approximately 2.0 Office Actions before an allowance. In contrast, those same examiners normally have approximately 3.6 Office Actions before issuing an allowance. The additional 1.6 Office Actions is significant because this represents at least one Request for Continued Examination (RCE). Once RCE practice is utilized, the duration in prosecution can significantly increase. ${ }^{57}$

\footnotetext{
${ }_{55}^{5}$ Shine Sean Tu, Three New Metrics for Patent Examiner Activity: Office Actions per Grant Ratio (OGR), Office Actions per Disposal Ratio (ODR) and Grant to Examiner Ratio (GER), 100 J. Pat \& Trademark Off. Soc'y 277 (2018).

5635 U.S.C. $\S 133$; See also MPEP $\S 710.01$ (stating "The maximum statutory period for reply to an Office action is 6 months. 35 U.S.C. 133. Shortened periods are currently used in practically all cases. See MPEP 710.02(b).”).

${ }^{57}$ James Cosgrove, How the Choice of a Rejection Response Can Impact Your Prosecution Timeline, JURIST, https://blog.juristat.com/2017/11/7/rejections-response-timings (stating that that "filing an RCE instead of an appeal following a first final rejection can significantly change the time to final disposition.").
} 
Figure 1

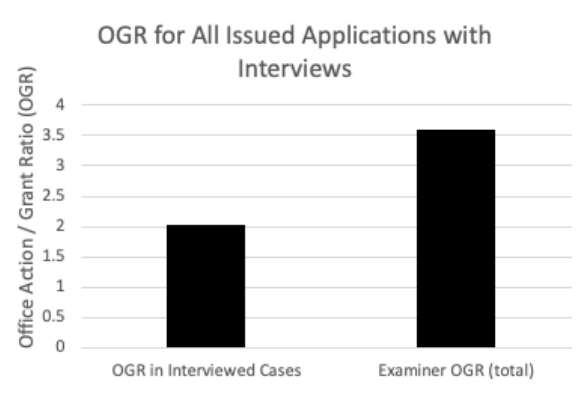

Figure 2 evaluates the issued application data by "applicant-initiated interviews" and Figure 3 reviews the issued application data by "examiner-initiated interviews." Applicant initiated interviews and examiner-initiated interviews were determined by the presence of a PTOL-413A or PTOL-413B form within the prosecution history, respectively.

Figure 2

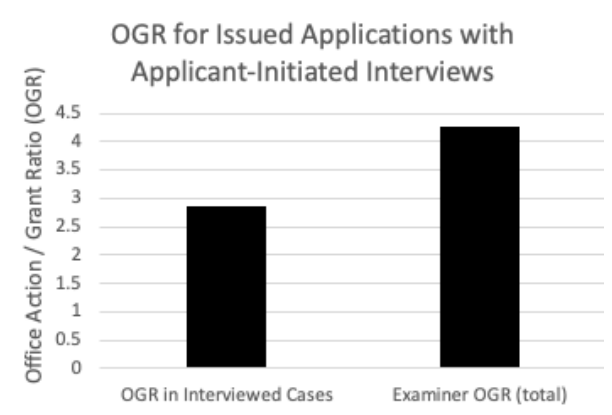

Figure 3

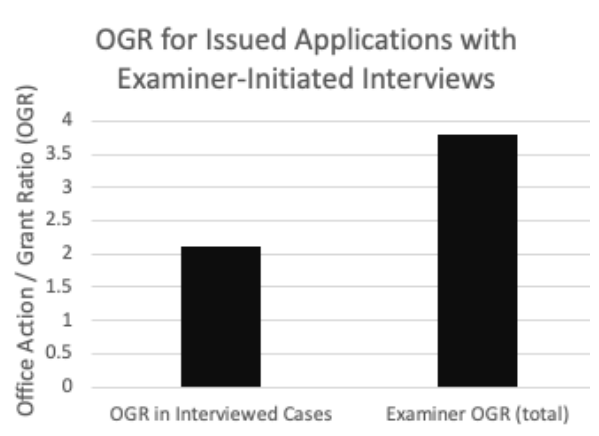

As shown in Figure 2, the OGR of 2.8 in cases with an applicant-initiated interview is significantly lower than the examiners' overall OGR of 4.2. Figure 3 shows a similar pattern for examiner-initiated interviews: a 2.1 OGR for cases with an interview compared to an overall OGR of 3.8. The examiner's OGR is slightly different between Figures 2 and 3 as the examiners in the applicant-initiated interview group are not identical to the examiner-initiated interview group. Interestingly, approximately 1.5 fewer Office actions are needed to get to allowance when using of an interview (whether applicant- or examiner-initiated).

Figure 4 


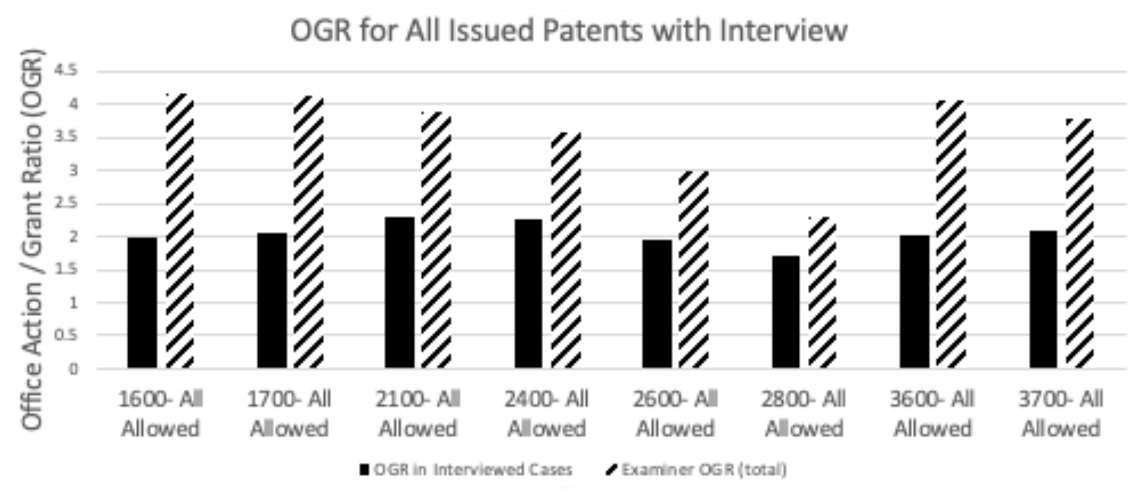

Finally, Figure 4 segments the allowance data by technology center. These data show that interview practice reduces the number of office actions required to get to allowance regardless of technology type. Unsurprisingly, interview practice has a significant influence on granted patents in technology centers 3600, 1600 and 1700, which customarily have lower allowance rates. Conversely, there is a smaller effect of interview practice on technology center 2800 , which has a high allowance rate.

Additionally, as shown in Appendix 1, the overall allowance rate for those applications that include interviews is not disproportionately greater than the overall allowance rate for the paired examiners, regardless of technology center. Accordingly, applications with interviews do not seem to have a significantly higher allowance rate than any other application; they just get to the allowance faster. These data suggest that interviews may help bridge the gap between interpretation of the prior art and/or understanding the invention.

\section{Abandoned Patents}

In contrast to allowance, the alternative "final" disposition for an application is abandonment. Application abandonment is almost completely under the control of the applicant. This is because even if an applicant receives a "final" rejection she may continue prosecution by simply filing an RCE. 58 Once an RCE is filed, generally the application can receive two additional office actions (typically one non-final action and one final action). This process can repeat itself again and again until either (1) the examiner allows the case or (2) the applicant decides to abandon the application.

If the examiner is unwilling to allow any claims in the application, it is better for the applicant to understand the examiner's rationale and quickly abandon the application rather than to cycle through multiple RCEs. This cycle of RCEs can cost the applicant thousands of dollars and additional months (sometimes years) in prosecution. Accordingly, this study examines if applications that include interviews help applicants abandon their applications faster.

To determine the effect of interviews on prosecution times, this study compares the OAR rates for those cases with interviews versus the corresponding total OAR rates for those same examiners. Accordingly, the OAR value for each interviewed application was compared against the OAR rate for that examiner. Similar to the OGR analysis in Section II(B), this pair-wise

\footnotetext{
${ }^{58}$ See Mark A. Lemley and Kimberly A. Moore, Ending Abuse of Patent Continuations, 84 B.U. L. Rev. 63 (2004).
} 
analysis prevents bias from incorporating data from examiners who do not interview any applications.

Figure 5 shows that cases with interviews that end up abandoned have approximately 2.5 Office Actions before the applicant abandons the application. In contrast, those same examiners normally require approximately 5.9 Office Actions before the applicant decides to abandon the application. The additional 3.4 Office Actions is significant because this represents two RCEs. Again, once RCE practice is utilized, the time in prosecution can significantly increase. 59

Figure 5

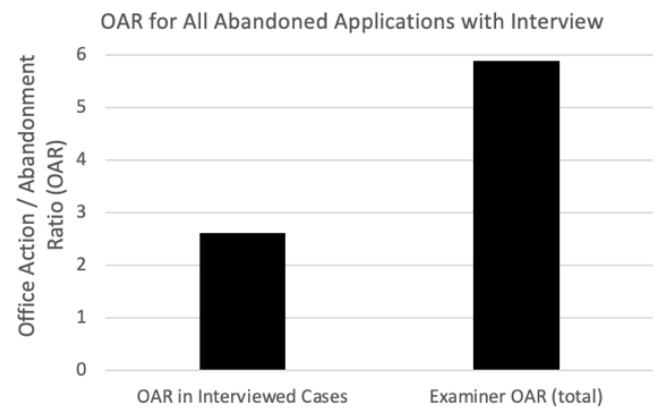

Figure 6 reviews the abandoned application data by "applicant-initiated interviews" and Figure 7 segments the data by "examiner-initiated interviews." As shown in Figure 6, when analyzing the data by applicant-initiated interviews, the OAR increases from 3.8 in interviewed cases to approximately 7.0 in general. Similarly, as shown in Figure 7, when segmenting the data by examiner-initiated interviews, the OAR increases from 3.0 in interviewed cases to 5.8 in the examiners' overall cases.

Figure 6

OAR for Abandoned Applications with Applicant Initiated-Interviews

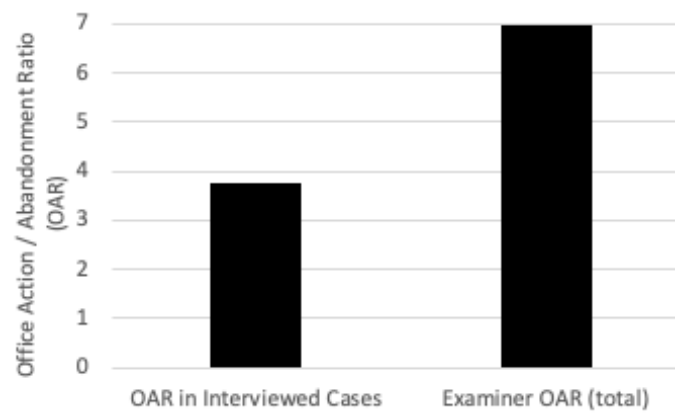

Figure 7

${ }^{59}$ Cosgrove, supra note 57 (stating that that "filing an RCE instead of an appeal following a first final rejection can significantly change the time to final disposition.”). 


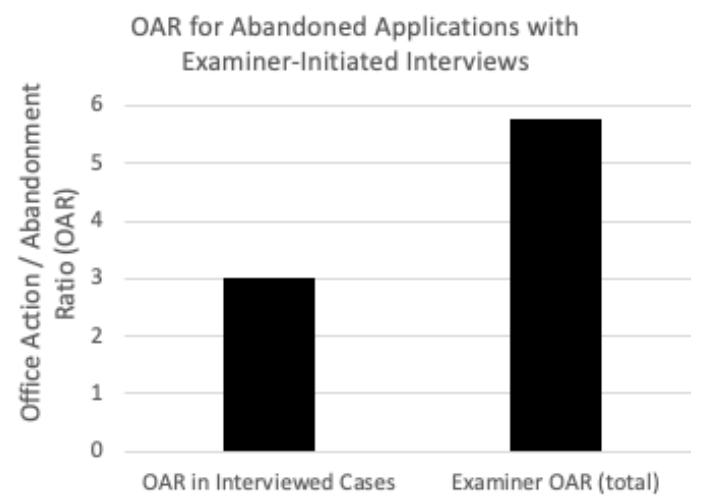

Similar to the OGR dataset shown in Figures 2 and 3, interviews result in significantly fewer Office Actions needed to get to a disposition (whether applicant or examiner-initiated). These data show a more pronounced effect of interviews on the applicant's decision to abandon their case than they are in convincing examiners to allow an application.

Finally, Figure 8 segments the abandonment data by technology center. These data show that interview practice reduces the number of office actions required to get to abandonment regardless of technology type. Similar to the results found for the allowance data, interview practice has a profound influence on the abandonment rates in technology centers 3600, 1600 and 1700, which customarily have lower allowance rates. Without the benefit of an interview, applicants in these technology centers may have to cycle through 5-7 additional Office Actions before deciding to abandon the application.

The addition of five to seven Office Actions likely results in at least two to three additional years in prosecution and thousands of dollars in prosecution fees as well as lost opportunity costs. ${ }^{60}$ These data also show that it is much more important for the applicant to request an interview to understand if the examiner will not allow the case (in contrast to interviews that help lead to allowance). This is because the number of Office Actions required to get the applicant understand that abandonment is the best option is much greater than the number of Office Actions necessary to get the examiner to allow the case. The main problem is that ex ante, it is difficult for the applicant to understand which road he will be traveling without an interview.

Figure 8

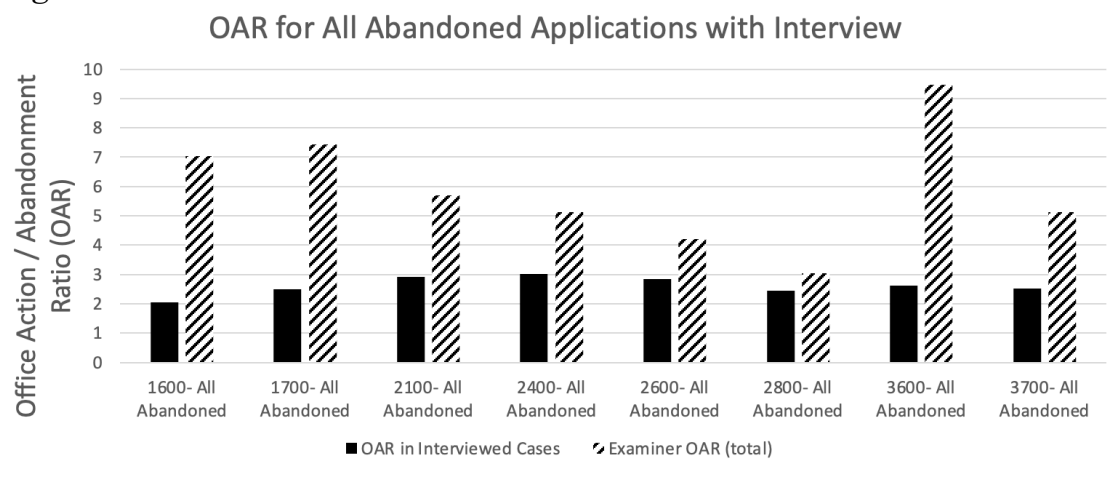

${ }^{60}$ Similar to the allowance rate data, Appendix 2 shows that the overall abandonment rates for those applications that include interviews is not disproportionately greater than the overall abandonment rates for the paired examiners, regardless of technology center. 


\section{IMPROVING INTERVIEW PRACTICE}

Interview practice can reduce the number of actions required to get to disposal. The three normative questions are: (1) why do interviews reduce the number of actions it takes to get to a disposal; (2) is it socially beneficial to incentivize interview practice; and (3) if we should, how do we incentivize interview practice?

\section{A. Rationales for How Interviews Compact Prosecution}

There are two non-exclusive rationales for why interview practice can compact prosecution. The first and most cited rationale is based on helping to bridge misunderstandings or miscommunications between the examiner and applicant. The second rationale is based on the signaling power of an interview.

\section{Interviews Used to Bridge the Gap}

The obvious explanation for an interviews' reduction in disposal times is that interviews help examiners understand applicants' arguments in a way that cannot be done in a paper response. Similarly, interview practice can also help applicants understand the examiners' concerns and/or confusion with the invention/prior art. Accordingly, the examiner may be more willing to work with the applicant to reach a disposal when an interview is conducted with particularly persuasive patent counsel.

Interviews allow applicants to display the invention to the examiner and demonstrate the invention in operation, as well as show the inventor how the invention works (by bringing a model or the actual invention to the interview). If an applicant brings in a model of the invention, the examiner may be able to better understand the invention and the nuances of the invention that cannot be explained in an Office Action response. Additionally, having the inventor or technical specialist come in to explain the inventive concept may help shed a different light on the invention for the examiner.

\section{Interviews as a Signal}

A second explanation for the reduction in Office Actions is that interviews act as a signal to the examiner that the application is especially valuable to the applicant. Specifically, examiners who have interviews where inventors are flown in from distant countries may recognize that this specific application might be important to the inventor/assignee and they will not easily drop their application. If an interview is conducted with a famous scientist, such as a Nobel Laureate, it might also signal to the examiner that the invention is novel. One firm, for particularly important cases, for example, reportedly would get a former PTO director to sit in on the interview for particularly important cases. Although I do not know what was discussed during the interview, most cases were allowed shortly after those interviews. ${ }^{61}$ Simply having the former PTO director in the room may have signaled to the examiner that the application was particularly important and worthwhile, whatever the examiner's personal reservations or questions.

\footnotetext{
${ }^{61}$ Personal communication from a former USPTO director. Similar stories have been told about John M. White, a renowned patent prosecutor.
} 
The interview, therefore, may act as a signal to the examiner that the applicant may be willing to force the examiner to review the application until an agreement is reached. This is especially important since only the applicant (and not the examiner) controls the abandonment process. Accordingly, applicants can control prosecution duration by forcing the examiner to review the case again and again by filing RCEs or continuation applications. ${ }^{62}$ This is important to the examiner because RCEs represent a lower production unit for the examiner. ${ }^{63}$

\section{B. Possible Improvements to Interview Practice}

Overall, both examiners and applicants are relatively happy with the current state of interview practice. On the examiner side, in an internal quality survey examiners stated that they were most happy with the "professional demeanor displayed in interview to advance prosecution" and they were also happy with the "preparedness [of the applicant] to efficiently and effectively conduct interviews." 64 On the applicant side, applicants seem very satisfied with interview practice, being most happy with examiner professionalism and preparedness. ${ }^{65}$

There are several relatively easy ways to improve interview practice. Specifically, the USPTO could require both applicants and examiners to come prepared with several different claim amendments to help move prosecution forward. Additionally, the USPTO could require a more detailed written record of what took place during the interview. To incentivize more interviews, the USPTO could make promotions up the GS pay scale at least partially dependent on examiners conducting a set number of interviews. Likewise, the USPTO could increase the non-prosecution time given to examiners from one hour to two hours to better reflect the amount of time needed to prepare for and conduct interviews.

\section{Require Proposed Claim Language from Both Applicants and Examiners}

In a survey conducted by the USPTO in 2018, both applicants and examiners were asked what was least satisfactory about interview practice. $84 \%$ of examiners and $75 \%$ of applicants were least satisfied with the discussion of "ways to overcome the rejection."66 From this survey, it seems as though both would like the other party to come up with solutions to resolve the issues brought up in the interview.

One way to help overcome this problem would be to require both the examiner and the applicant to bring concrete claim language to the interview. These claims could be used as a starting point for discussions as well as to help guide the examiner and the applicant on the road to resolution. New claim language proffered by the applicant would help the examiner understand the inventive step or the important nuances in the claimed invention that may help distinguish the invention from the prior art. Additionally, newly tendered claim language from the examiner may help the applicant better understand how the examiner is interpreting the claimed invention or the prior art.

\footnotetext{
62 See generally Mark A. Lemley \& Kimberly Moore, Ending Abuse of Patent Continuations, 84 B.U. L. REV. 63, 75 (2004) (stating that "[s]ince an examiner can only finally dispose of an application by allowing it, an examiner faced with a determined applicant has every incentive to give in and allow the patent.").

${ }^{63}$ Shine Tu, Patenting Fast and Slow: Examiner and Applicant Use of Prior Art, 38 CARDOZO ARTS \& ENT. L.J. 391 (2020).

${ }^{64}$ USPTO Internal Quality Survey, Fiscial Year 2021 Quarter 2. See also "A Conversation with the Commissioner: A Look Inside Patent Processes at the USPTO” IP Watchdog webinar, July 15, 2021, slide 12.

${ }^{65}$ See PTO Interview Policy Presentation "Partnering in Patents: Interview Practice" Tariq Hafiz, Director Technology Center 3600 (Slide 22).

${ }^{66}$ See PTO Interview Policy Presentation "Partnering in Patents: Interview Practice" Tariq Hafiz, Director Technology Center 3600 (Slide 22).
} 


\section{Create a More Detailed Interview Summary}

Frequently, the interview summary drafted by the examiner is fairly brief and does not contain information that can be used for prosecution history estoppel. This is especially true when applicants and examiners jointly write the summary. Accordingly, the applicant usually suggests language that is broad and intentionally opaque. Some interview summaries contain language as simple as, "Discussed 102 and 103 rejections." By using such broad language, applicants essentially move prosecution forward without generating a detailed prosecution history that could later be used against them in litigation. This is especially problematic if the applicant made arguments and/or representations at the interview that limit claim interpretations.

Although this lack of a detailed prosecution history can be advantageous to the patentee, it is more problematic for the public and competitors. Applicant statements usually become part of the prosecution history and can later play a key role for courts in both claim interpretations as well as interpreting the prior art. When these statements are made verbally in interviews without a written or digital record, they do not appear in the prosecution history. Without these statements as part of the record, the applicant gets the benefit of overcoming the rejection while the public (and competitors) loses the benefit of statements to help delineate the boundaries of the claim. Accordingly, claim interpretation becomes less accurate and less predictable, and the allowed claims may be interpreted more broadly than what was envisioned by both the examiner and the applicant.

Similarly, lack of a record could make claim interpretation of the doctrine of equivalents more difficult. The doctrine of equivalents protects inventors from infringers who try to "evade liability for infringement by making only insubstantial changes to a patented invention" to avoid literal infringement. 67 For example, a patentee is estopped from asserting infringement under the doctrine of equivalents if the applicant agrees to make a narrowing amendment to overcome a prior art rejection. If the rationale for the amendment is not present in the interview record, then applicants can argue that the amendment "bears no more than a tangential relation to the [alleged] equivalent" in question. ${ }^{68}$ Without a record describing the rationale for the amendment, courts will not "speculate on the reasons for the cancellation" or amendments. ${ }^{69}$ Accordingly, without a record of what occurred during the interview, courts will not hypothesize on the rationales for claim amendments / cancellations that could help interpret the meaning and scope of the claim.

One way to quickly improve interview practice is to require examiners to create a more detailed summary of what occurred in the interview. This should be written independently by the examiner with little input from the applicant. The applicant, of course, should be able to respond to the examiner interview if the applicant believed the summary did not reflect the discussion at the interview. This could simply be done in the next Office Action response by the applicant or in a separate interview summary.

Alternatively, an audio or video recording of the interview could be made part of the prosecution record. Since most interviews are conducted telephonically, a simple audio

${ }^{67}$ Festo Corp. v. Shoketsu Kinzoku Kogyo Kabushiki Co., 535 U.S. 722 (2002).

68 Bio-Rad Laboratories, Inc. v. 10 X Genomics Inc., 967 F.3d 1353, 1364 (2020); see also Festo Corp. v. Shoketsu Kinzoku Kogyo Kabushiki Co., 122 S.Ct. 535 U.S. 722 (2002).

69 Unique Concepts, Inc. and Brown, 939 F.2d 1558, 1563 (1991); see also https://patentlyo.com/patent/2014/04/examinerinterviews-transparent.html (2014). 
recording of the interview that is included in the image file wrapper could help courts, competitors and the public determine the metes and bounds of the claimed invention. Furthermore, the audio from face-to-face interviews conducted via the USPTO's WebEx application or in-person interviews should also be easily recordable. By attaching either a recording or a transcript, there would be a completely accessible record of exactly what limitations, amendments, and agreements were discussed.

\section{Tie Interview Practice to Examiner Promotion}

To incentivize interviews and interview competency, the USPTO could require a specific number of interviews before allowing promotion to the next GS level. If the USPTO believes that interview practice helps to compact prosecution, then it should require all examiners to have experience with interview practice. Supervisory examiners could also be required to mentor, review, and critique the junior examiner's administration of the interview. Only those examiners proficient in conducting effective interviews would be promoted to the next level. Thus, all primary examiners with signatory authority would be experienced and adept at directing interviews.

\section{Increase the Examiner Time Allotted for Interview Practice}

One way to easily incentivize examiner interviews is to increase the amount of nonproduction time that the examiner can count towards interview practice. Currently, examiners can only claim one hour towards examiner interviews. Non-production time currently goes up in one-hour increments. Accordingly, examiners would potentially get two hours of non-production time for conducting an interview.

Increasing the amount of time to two hours would allow examiners to better review the applicants' arguments and/or review the prior art and the claimed invention. The additional time could also be used to enhance interview practicing by creating a more detailed examiner interview summary or drafting claims that could overcome specific rejections. Specifically, if the USPTO required the examiner to draft an interview summary of at least 500 words and draft at least one claim that could address a rejection, then the examiner should be credited an additional hour of non-production time.

Increasing the allotted time available to examiners for interview practice is not costless. This would significantly increase the costs associated with prosecution. If more examiners utilize interview practice and the USPTO gives examiners two hours of non-production time instead of only one, then examination costs would increase significantly. With that said, if interviews result in the allowance of better claims in a shorter amount of time, these costs may be absorbed because the USPTO makes more revenue from maintenance fees than from user fees associated with examination. ${ }^{70}$ In fact, maintenance fees are the largest source of earned revenue by the USPTO, and, without them, it would be operating at a loss. ${ }^{71}$

\footnotetext{
70 See 2020 Performance and Accountability Report, United STATEs PATENT AND TRADEMARKs OfFICE, 36 (2020) (showing that revenue from maintenance fees accounted for an estimated $\$ 1,663.3$ million (49.9\% of total revenue), and "[maintenance fees] play a large part in whether a total net income or net cost is recognized."). See also Michael D. Frakes \& Melisasa F. Wasserman, Does Agency Funding Affect Decisionmaking?: An Empirical Assessment of the PTO's Granting Patterns, 66 VAND, L. REV. 67, 79 (2013) (stating "the PTO is heavily dependent on issuance fees and maintenance fees, which account for over $50 \%$ of the PTO's patent budget, to fund its operations.").

${ }^{71}$ See 2020 Performance and Accountability Report, supra note 70, at 40.
} 


\section{Social Justice and Examiner Interviews}

Interviews also have the potential for helping reduce the demonstrated socio-economic, racial, and gender disparities among patentees. It has previously been shown that women and African Americans patent at a rate much lower than men. ${ }^{72}$ For example, in a 2006 study, Waverly Ding showed that female life science faculty members patented at a rate of only $40 \%$ of their male counterparts. ${ }^{73}$ Researchers have also shown that individuals born to wealthier parents are far more likely to patent than individuals born to poorer patents. ${ }^{74}$ These wealth and diversity disparities are important because it could correlate with access to legal counsel who understand the patent process and how / when to use examiner interviews.

To address pro se applicants, the PTO created the "Pro Se Assistant Program" and Art Unit 3649 as a pilot program in October of 2014. The idea was to make the patent system more transparent to underrepresented patent applicants and to encourage innovation by increasing accessibility to patent protection. The program already offers phone, email, in-person and video conferencing help to those applicants at the pre-filing stage. ${ }^{75}$ Although this helps during the pre-filing stage, encouraging interviews could further support minority applicants during the patenting process itself.

One solution to help balance inequities is for examiners to initiate more interviews sua sponte with pro se applicants. For example, extending the Pro Se Assistance Program to require at least one examiner-initiated interview before imparting a final Office Action may help alleviate some inequities created by those applicants who can afford a patent agent or patent attorney to help prosecute the patent.

Pro se applicants may not be aware of their rights or that they even have the ability to speak directly with their examiner. Help for pro se applicants with examiner-initiated interviews is especially relevant since, as shown in Appendix $3 \mathrm{~A}$ and $3 \mathrm{~B}$, most interviews are initiated by the applicant. In fact, applicants-initiated interviews almost twice as frequently as examiners. Additionally, most of the examiner-initiated interviews came at the very end of the prosecution process when only small amendments were needed to be made for allowance. Accordingly, requiring the examiner to initiate at least one interview with the pro se applicant before delivering a final office action may help pro se inventors understand the rejections and arguments from the examiner and help make the patenting process more transparent to those who do not regularly interact with the patent office.

\section{CONCLUSION}

This study empirically shows that examiner interviews compacts prosecution saving applicants time and money. However, the rationale for what may motivate an examiner to allow a case after an interview may vary. One positive rationale may simply be that the interview bridges the gap of knowledge between the inventor and the examiner. On the negative side, the examiner may allow a case because the interview signaled to the examiner that the inventor

\footnotetext{
${ }^{72}$ Holly Fechner and Matthew S. Shapanka, Closing Diversity Gaps in Innovation: Gender, Race and Income Disparities in Patenting and Commercialization of Inventions, 19 TECH. \& INNOVATION 727 (2018); Lisa D. Cook, Inventing Social Capital: Evidence from African American Inventors, 1843-1930, 48 ExplORATIONS IN ECON. History 507 (2011); Waverly W. Ding, Fiona Murray, Toby E. Stuart, Gender Difference in Patenting in the Academic Life Sciences, 313 ScI. 665 (2006).

${ }^{73}$ Ding, surpra note 72

${ }^{74}$ Fechner and Shapanka, supra note 72 , at 729.

75 See FY 2020 US Patent and Trademark Office - Performance and Accountability Report at 69.
} 
would not easily abandon the application, thus cluttering up the examiner's docket for a longer amount of time while lowering their productivity rate. Accordingly, we should modify interview practice to incentivize the use of interviews to bridge the knowledge gap while protecting the public from patents that may be allowed due only signals from the interview.

Encouraging interviews to make the patenting process more efficient, cost-effective, and productive can be easily achieved by implementing this study's suggestions. The USPTO would be able to see tangible benefits by requiring both applicants and examiners to bring concrete claim amendments to the interview, forcing both applicants and examiners to create a more detailed interview summary, tying interview practice to examiner promotion, increasing the time allotted for interviews, and requiring examiners to initiate interviews with each of their pro se applicants. 
Appendix 1

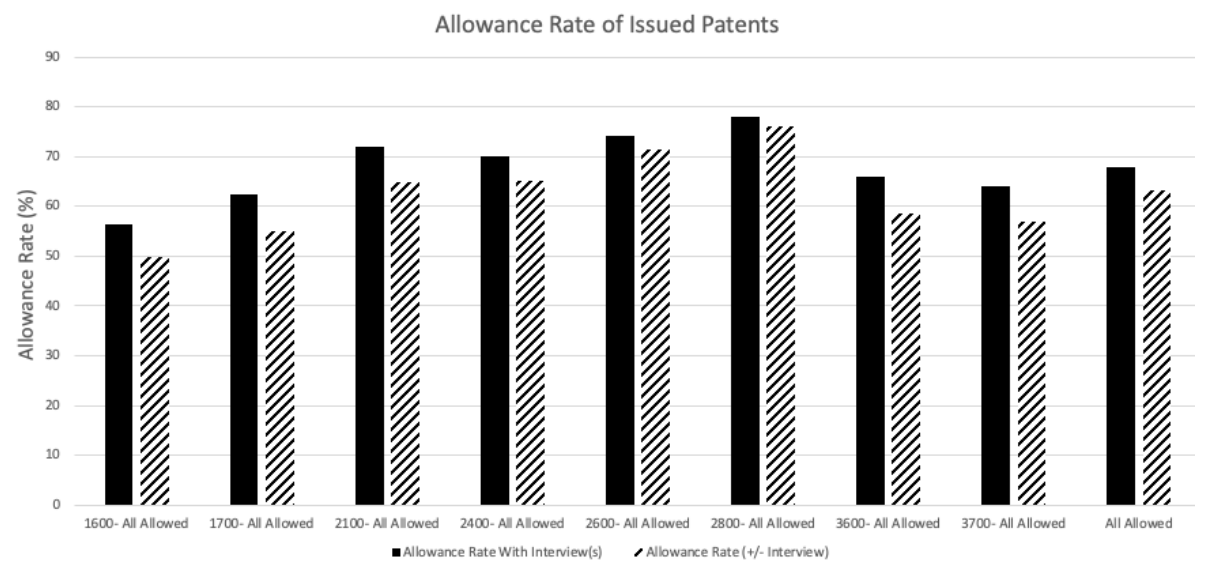

Appendix 2

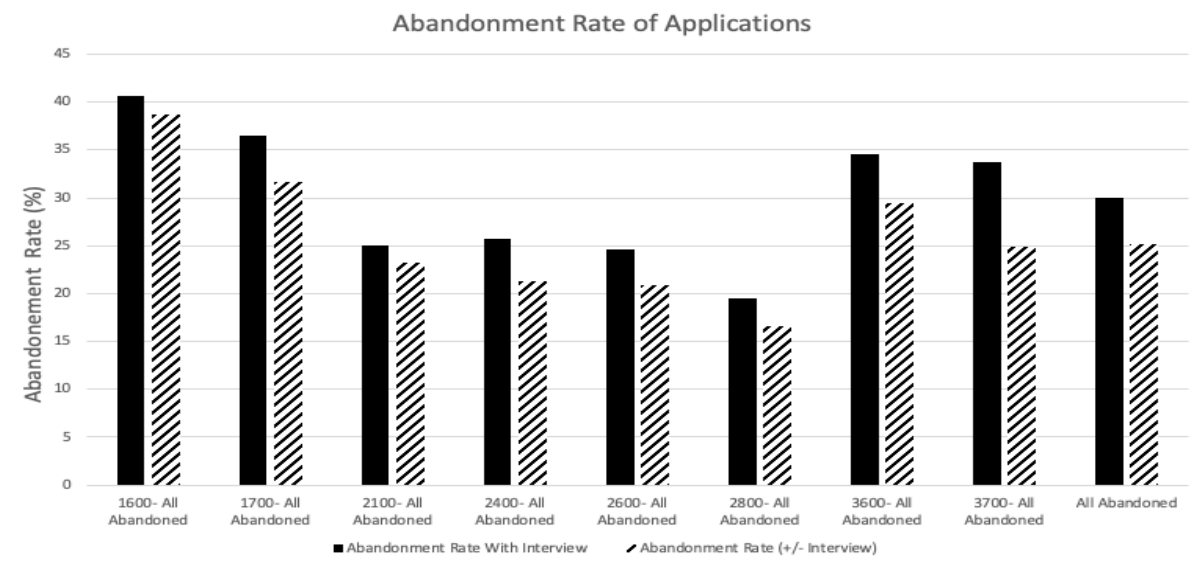

Appendix 3A

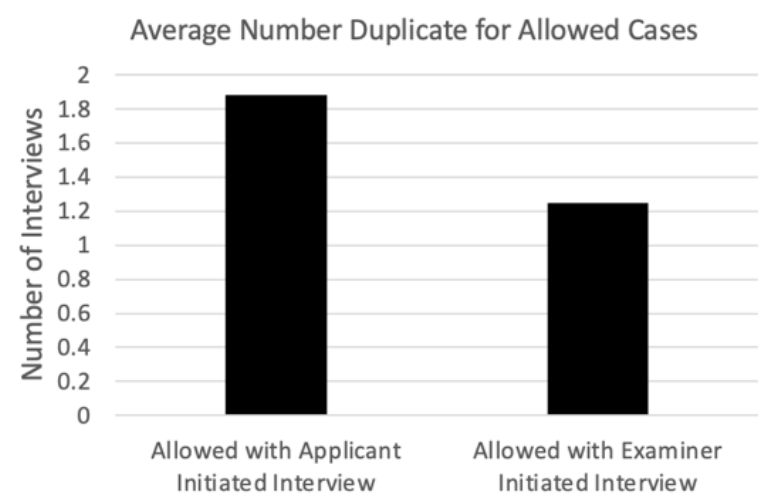

Appendix 3B 


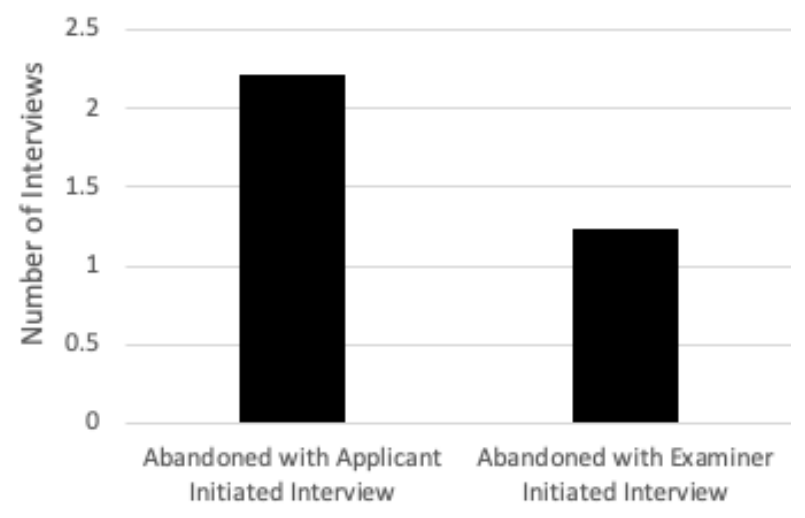

Appendix 4

\section{Full First Action Interview Pilot Program (FAIPP)}

The USPTO recognizes the importance of interview practice. Accordingly, the USPTO created a pilot program to determine if interviews prior to the first Office action reduces prosecution times. Specifically, the program is intended to "expedite disposition of an application by enhancing communication between an applicant and an examiner at the beginning of the examination process." 76 Currently, the FAIPP is open to all technology areas and filing dates. ${ }^{77}$

To enroll in this pilot program there are six requirements: (1) the application cannot be a reissue or provisional or national stage of an international application, (2) the application must contain three or fewer independent claims and no more than twenty total claims, (3) the application cannot contain any multiple dependent claims, (4) the application must be directed to a single invention, and the applicant agrees to make an election without traverse if the Office determines that the claims are not obviously directed to a single invention, (5) the request for a first action interview must be filed electronically and must be filed at least one day before a first Office action on the merits appears in the Patent Application Information Retrieval (PAIR) system, and (6) the applicant agrees not to request a refund of the search fees and any excess claim fee paid in the application after the mailing or notification of the pre-interview communication made by the examiner.

Under this program, applicants first receive the examiner's search results and a condensed preinterview communication. The communication contains relevant prior art and identifies proposed rejections and/or objections. Withing 30 days of receipt of the communication, the applicant schedules an interview and submits proposed amendments and/or arguments.

The parties then conduct an interview with the examiner prior to the first Office Action. The interview should focus on three things: (1) to help the examiner better understand the invention; (2) to establish the state of the art at the time of the effective filing date, including the prior art references cited by both the applicant and examiner, and/or (3) to help the examiner understand the features of the claimed subject matter which make the invention patentable, including any proposed amendments to the claims. ${ }^{78}$ The substance of the interview

7677 Federal Register 40342 (2012).

77 Originally, the "Enhance First Action Interview Pilot Program" was limited by technology area and filing date. See also Full First Action Interview Pilot Program, United States Patent And TRADEMARK OfFICE (Feb. 26, 2015).

7880 Federal Register 39758, section IX(A) (2015). 
must be made of record and a complete written statement with the substance of the interview with regard to the merits of the application is made of record. ${ }^{79}$

The PTO outline three possible outcomes from the First Action Interview. The first outcome is the best-case scenario for the applicant. An agreement is reached, and all claims are in condition for allowance. The examiner will complete an Interview Summary (PTOL-413), enter and attach any necessary amendments or arguments, and the completed forms will be made of record with a Notice of Allowance and Fees Due.

A second possible outcome is that an agreement as to allowability is not reached. If this is the case, the examiner will set forth any unresolved, maintained or new requirements, objections, and/or rejections in the First Action Interview Office Action. ${ }^{80}$ The examiner will then complete an Interview Summary "highlighting the basis for any unresolved, maintained, or new requirements, objections and rejections as well as resolution of any issues that occurred during the interview." 11 This First Action Interview Office Action will be considered the first Office Action on the merits. The applicant, then respond within two months (or sixty days, whichever is longer), which can be extended for up to two additional months.

Finally, the third possible outcome is that an agreement as to allowability is not reached, and the applicant converts the previously submitted proposed amendment into a reply under 37 CFR 1.111(b) and waives receipt of a First Action Interview Office Action. ${ }^{82}$ If the examiner agrees to enter the amendment as the reply, then the First Action Interview Office Action will not be provided to the applicant. The Pre-Interview Communication and the interview will be deemed the first Office Action on the merits. The examiner will enter the proposed amendment, and/or arguments, and consider it as the reply under 37 CFR 1.111, and provide an Office action in response to that reply. 83

Although many applicants do not avail themselves of this program, it works surprisingly well for those applicants who do use the program. The results from the Original and Enhanced First Action Interview Pilot in April 26, 2011, showed that the first action allowance rate was $33.5 \% .84$ Similarly, the current FAIPP shows a $29 \%$ first action allowance rate compared to a $14 \%$ first action allowance rate for new, non-continuing application. ${ }^{85}$ Additionally, the rate of an allowance in the next action increases to $36 \% .{ }^{86}$ Gilles found that of the approximately 8800 FAIPP applications filed between 2010 and 2018, 94\% were allowed. In contrast, the overall allowance rate for applications was $76 \% .87$

\footnotetext{
79 MPEP § 713.04.

8080 Federal Register 39758, section IX(B) (2015). See also Official Gazette of the United States Patent and Trademark Office, USPTO, https://www.uspto.gov/web/offices/com/sol/og/2011/week23/TOC.htm\#ref11 (visited July 15, 2021).

${ }^{81} I d$.

${ }^{82} I d$.

${ }^{83} \mathrm{Id}$.

${ }^{84}$ Full First Action Interview (FFAI) Pilot Program presentation, https://www.uspto.gov/patent/initiatives/first-actioninterview/full-first-action-interview-pilot-program, slide 15 (last visited August 4, 2020).

85 https://www.uspto.gov/dashboard/patents/special.html (last visited August 15, 2021). See also Paul Calvo, Global Patent Prosecution - November 2020: The USPTO's First Action Interview Pilot Program, JD SuPRA (Nov. 30, 2020), https://www.jdsupra.com/legalnews/global-patent-prosecution-november-2020-88077/ (stating a 35\% first action allowance rate as of November 2020).

${ }^{86}$ Chad Gilles, Why Are You Not Taking Advantage of the First Action Interview Pilot Program?, BIG PATENT DATA (June 13, 2018), https://bigpatentdata.com/2018/06/why-are-you-not-taking-advantage-of-the-first-action-interview-pilot-program/. ${ }^{87}$ Id. See also, Chad Giles, Do Examiner Interviews Live Up to the Hype, Big PATENT DATA (June 12, 2018), https://bigpatentdata.com/2018/06/do-examiner-interviews-live-up-to-the-hype/; Tia Brand, First Action Interview (FAI) Pilot Program Usage Remains Low, HARRITY, https://harrityllp.com/first-action-interview-fai-pilot-program-usage-remains-low/.
} 